\title{
A retrospective study evaluating the pretreatment tumor volume (PTV) in non-small cell lung cancer (NSCLC) as a predictor of response to program death-I (PD-I) inhibitors
}

This article was published in the following Dove Press journal:

Lung Cancer: Targets and Therapy

\author{
Misako Nagasaka (D) ${ }^{1,2}$ \\ Nadine Abdallah (iD) ${ }^{3}$ \\ Marcus Crosby ${ }^{4}$ \\ Nithin Thummala' \\ Dhaval Patel' \\ Antoinette J Wozniak ${ }^{5}$ \\ Shirish Gadgeel ${ }^{6}$ \\ Judith Abrams' \\ Ammar Sukari (iD) \\ 'Department of Oncology, Karmanos \\ Cancer Institute, Wayne State University, \\ Detroit, MI, USA; ${ }^{2}$ Department of \\ Advanced Medical Innovations, St. \\ Marianna University Graduate School of \\ Medicine, Kawasaki, Japan; ${ }^{3}$ Department \\ of Internal Medicine, Wayne State \\ University, Detroit, MI, USA; \\ ${ }^{4}$ Department of Radiation Oncology, \\ Gundersen Health System, La Crosse, \\ WI, USA; ${ }^{5}$ Department of Oncology, \\ University of Pittsburgh, Pittsburgh, PA, \\ USA; ${ }^{6}$ Department of Internal Medicine, \\ Division of Hematology and Oncology, \\ University of Michigan, Ann Arbor, \\ MI, USA
}

Introduction of hypothesis: Little information is available regarding the imaging characteristics that assist in differentiating responders from non-responders. We hypothesized that patients with higher pretreatment tumor volume (PTV) would have lower response rates and shorter overall survival (OS).

Methods: Data from patients who received at least one dose of program death-1 (PD-1) inhibitors before August 31, 2016 were captured from our institution's pharmacy database. The primary objective was to determine the association of PTV with best response, evaluated utilizing RECIST v1.1 criteria. Secondary objectives were estimation of progression-free survival (PFS) and OS. PTV was measured using the Philips Intellispace Multi-Modality Tumor Tracking application.

Results: 116 non-small cell lung cancer (NSCLC) patients were evaluated. 66\% patients had adenocarcinoma, $28 \%$ had squamous cell carcinoma and $5 \%$ had poorly differentiated NSCLC. Median PTV was $53.7 \mathrm{~cm}^{3}$ (95\% CI: 13.3-107.9). Only one individual had no metastases and the remainder had M1 disease; 38\% M1a, 10\% M1b, 51\% M1c. Most (79\%) were previously treated. There were no complete responses; among those followed for at least 6 weeks, 26\% had a partial response, 39\% stable disease and 34\% PD; $4 \%$ had no recorded response. There were no strong associations of PTV with any of the demographic or clinical characteristics. There was no association between PTV and OS (HR 1.2, $P=0.26$ ) or PFS (HR 1.1, $P=0.47$ ). Liver metastasis was associated with shorter survival $(\mathrm{HR}=2.8, P=0.05)$.

Conclusion: PTV in NSCLC did not prove to be a predictor of response to PD-1 inhibitors but having liver metastasis was associated with significantly shorter survival.

Keywords: non-small cell lung cancer, tumor volume, tumor burden, checkpoint inhibitors

\section{Plain language summary}

- Little information is available regarding the imaging characteristics that may assist in differentiating patients with non-small cell lung cancer who respond to immunotherapy and those who do not.

- We hypothesized that the more tumor volume the patient had, the lower their response to immunotherapy would be.

- Contrary to our hypothesis, tumor volume in non-small cell lung cancer did not prove to be a predictor of response to immunotherapy.

- However, cancer spread to the liver which was known prior to treatment was associated with significantly shorter survival.
Department of Oncology, Karmanos

Cancer Institute, Wayne State University,

4100 John R, Detroit, MI 4820I, USA

Tel +1 3135768753

$\mathrm{Fax}+$ I 3135768699

Email sukaria@karmanos.org 
- We believe that the concept and methodology of this study may be valuable to other researchers/clinicians who are involved in the treatment of non-small cell lung cancer.

\section{Introduction}

Program death-1 (PD-1) inhibitors are anti-cancer treatments that aim to reinstate anti-cancer immune-mediated cytotoxicity in individuals with cancer. Although this class of therapy offers hope for many patients with advanced stage cancer, little information is available regarding the imaging characteristics that assist in differentiating responders from non-responders. Several studies have shown that higher pretreatment metabolic tumor volume was associated with worse prognosis in non-small cell lung cancer (NSCLC) patients treated with definitive chemoradiotherapy. ${ }^{1,2}$ However, data on the utility of pretreatment tumor volume (PTV) in assessing response to immunotherapy are lacking.

In patients with metastatic renal cell carcinoma, prior nephrectomy has been associated with improved survival and treatment response to systemic therapy, including targeted therapy and immunotherapy like interferon- $\alpha$ $($ INF- $\alpha) .^{3-6}$ Similarly, Huang et al reported that in patients with metastatic melanoma, clinical failure to pembrolizumab was not solely due to an inability to induce immune reinvigoration, but rather resulted from an imbalance between $\mathrm{T}$-cell reinvigoration and actual tumor burden. ${ }^{7}$ Therefore, we hypothesized that NSCLC patients with higher PTV would have lower response rates (RRs) and shorter overall survival (OS) independent of other variables such as age and category of metastasis (i.e., M1a, M1b, M1c).

\section{Materials and methods}

Data from patients who received at least one dose of PD-1 inhibitors before August 31, 2016 were captured from our institution's pharmacy database. Of note, August 3, 2011 was the first date a patient had PD-1 inhibitor administered on trial, which provided us approximately 5 years of treatment data. For patients on trial, the institution's clinical trial database was used to find all studies involving PD-1 inhibitors. The database was searched using the commercially available name or the drug identification number assigned by the manufacturer. The pharmacy dispensing database was used to validate the first dispense date of drug. For commercially available PD-1 inhibitors, the database was reviewed to identify order data and then nursing records were used to validate administration of drug on that date. The primary objective was to determine the association of PTV with best response, evaluated utilizing RECIST v1.1 criteria. Secondary objectives were estimation of progression-free survival (PFS) and OS. Tumor PD-L1 status was not assessed. This study was reviewed and approved by the Wayne State University's Institutional Review Board (approval \# 062616M1E).

PTV was measured using the Philips Intellispace Multi-Modality Tumor Tracking application (Figure 1). The sum of PTV of all measurable lesions, as defined by any soft tissue mass at or $>2 \mathrm{~cm}$ in largest diameter and any lymph nodes at or $>1.5 \mathrm{~cm}$ in shortest diameter, were calculated based on this software and were reported in cubic centimeters. Any soft tissue masses $<2 \mathrm{~cm}$ in largest diameter were documented as unmeasurable soft tissue mass and categorized in a binary fashion; yes when such lesions were present and no when they were not.

PTV was found to have an asymmetric frequency distribution which was remedied by a natural loc (ln) transformation. Kendall's tau-b was used to assess the association between best clinical response and PTV. Univariable proportional hazards were used to assess associations with OS. Multivariable proportional hazard models were not estimated because there were only 47 deaths among the 133 individuals in the dataset.

\section{Statistical consideration}

Because the shape of the distribution of total volume was not symmetric, the non-parametric Kruskal-Wallis test was used to compare tumor volume between groups defined by nominal variables such as sex and primary histology. Spearman's rank correlation was used to estimate the association between tumor volume and ordered measures such as metastatic category and age. Analyses of "best response" and "hospitalization within 6 weeks" were restricted to individuals with at least 6 weeks of follow-up. Univariable proportional hazard models were used to estimate the association of each of the demographic and clinical characteristics with PFS and OS. Caution is urged in the interpretation of reported $p$-values because no correction for multiplicity was applied.

\section{Results}

116 NSCLC patients with at least one site of measurable disease were evaluated. Entry was restricted to individuals who had received at least one dose of a PD-1 or PD-L1 inhibitor prior to the data cut-off of August 31, 2017. Median age was 63 (IQR: 57-70); 67 (58\%) were male. $66 \%$ patients had adenocarcinoma, $28 \%$ had squamous cell 


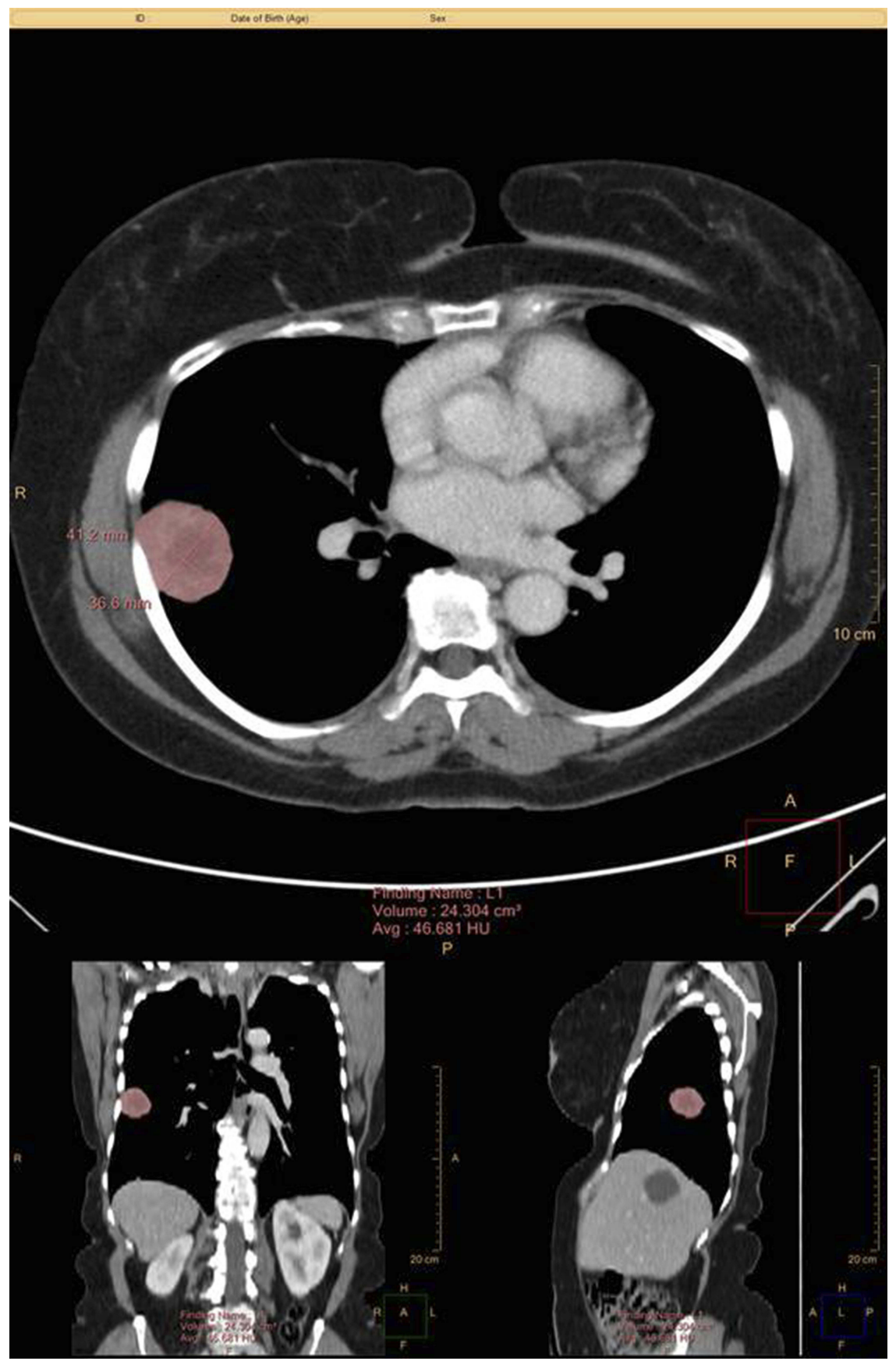

Figure I Example PTV measurement using the Philips Intellispace Multi-Modality Tumor Tracking (MMTT) application.

carcinoma and 5\% had poorly differentiated NSCLC (Table 1). More than half $(56 \%)$ received Nivolumab with the remainder receiving Pembrolizumab either alone $(18 \%)$ or in combination (26\%). $45(39 \%)$ were treated on a clinical trial. Only one individual had no metastases and the remainder had M1 disease; $38 \% \mathrm{M} 1 \mathrm{a}, 10 \% \mathrm{M} 1 \mathrm{~b}, 51 \%$ M1c. Most (79\%) were previously treated. There were no complete responses; among those followed for at least 6 weeks, 26\% had a partial response (PR), 39\% stable disease (SD) and 34\% PD; 4\% had no recorded response. Among those followed for at least 6 weeks, 24\% were hospitalized within 6 weeks of their first dose. Overall, median total tumor volume was $53.7 \mathrm{~cm}^{3}(95 \%$ CI 13.3 , 107.9). There were 52 deaths and 90 PFS events among the participants. Median follow-up time for those alive at last follow-up was 27 months (95\% CI: 21, 31).

There were no strong associations of total volume with any of the demographic or clinical characteristics (Table 2). 
Table I Demographic and clinical characteristics

\begin{tabular}{|c|c|}
\hline & $N=116$ \\
\hline Sex & \\
\hline Male & $67(58 \%)$ \\
\hline Female & 49 (42\%) \\
\hline Age & \\
\hline Median (IQR) & $63(57,70)$ \\
\hline Primary & \\
\hline Lung adeno & 77 (66\%) \\
\hline Lung squam & $33(28 \%)$ \\
\hline Lung poorly diff & $6(5 \%)$ \\
\hline Mets category & \\
\hline Mo & I (I\%) \\
\hline Mla & $44(38 \%)$ \\
\hline MIb & $12(10 \%)$ \\
\hline MIc & $59(51 \%)$ \\
\hline Number of lines of previous tx & \\
\hline 0 & $24(21 \%)$ \\
\hline I & $64(55 \%)$ \\
\hline 2 & $23(20 \%)$ \\
\hline 3 & $2(2 \%)$ \\
\hline 4 & $2(2 \%)$ \\
\hline 5 & $\mathrm{I}(\mathrm{I} \%)$ \\
\hline Agent & \\
\hline Pembro & $21(18 \%)$ \\
\hline Pembro plus chemo & $15(13 \%)$ \\
\hline Pembro plus investigational & $7(6 \%)$ \\
\hline Pembro plus ipi & $8(7 \%)$ \\
\hline Nivo & $65(56 \%)$ \\
\hline Protocol & \\
\hline No & $71(61 \%)$ \\
\hline Yes & $45(39 \%)$ \\
\hline Best response $\mathrm{a}^{\mathrm{a}}$ & \\
\hline PR & $26(26 \%)$ \\
\hline SD & $39(39 \%)$ \\
\hline PD & $34(34 \%)$ \\
\hline Not recorded & $4(4 \%)$ \\
\hline Reason for discontinuation & \\
\hline Progression & $37(32 \%)$ \\
\hline PD-I Adverse events & $16(14 \%)$ \\
\hline PS Decline, hospital admit, hospice & $43(37 \%)$ \\
\hline Completed therapy & II (I0\%) \\
\hline Unknown, lost & $6(5 \%)$ \\
\hline Long vacation & $\mathrm{I}(\mathrm{I} \%)$ \\
\hline No response & $2(2 \%)$ \\
\hline Hospitalization within 6 weeks of first dose ${ }^{a}$ & \\
\hline No & $78(76 \%)$ \\
\hline Yes & $25(24 \%)$ \\
\hline
\end{tabular}

(Continued)
Table I (Continued).

\begin{tabular}{|l|l|}
\hline & $\mathbf{N}=116$ \\
\hline $\begin{array}{l}\text { Total volume, median (IQR) } \\
\text { Median (IQR) }\end{array}$ & $53.7(13.3,107.9)$ \\
\hline $\begin{array}{l}\text { Lung volume } \\
\text { Median (IQR) }\end{array}$ & $15.1(0.0,65.4)$ \\
\hline $\begin{array}{l}\text { Unmeasurable lung } \\
\text { Yes }\end{array}$ & $27(23.3 \%)$ \\
\hline $\begin{array}{l}\text { LN volume } \\
\text { Median (IQR) }\end{array}$ & $89(76.7 \%)$ \\
\hline $\begin{array}{l}\text { Unmeasurable LN } \\
\text { No } \\
\text { Yes }\end{array}$ & $5.1(0.0,18.1)$ \\
\hline $\begin{array}{l}\text { Liver volume } \\
\text { Median (IQR) }\end{array}$ & $43(37.1 \%)$ \\
\hline $\begin{array}{l}\text { Unmeasurable liver } \\
\text { No } \\
\text { Yes }\end{array}$ & $73(62.9 \%)$ \\
\hline $\begin{array}{l}\text { Soft tissue volume } \\
\text { Median (IQR) }\end{array}$ & $0.0(0.0,0.0)$ \\
\hline $\begin{array}{l}\text { Ynmeasurable soft tissue } \\
\text { No }\end{array}$ & $93(80 \%)$ \\
\hline
\end{tabular}

Notes: ${ }^{\text {aFor }}$ those followed for at least weeks.

Abbreviations: SD, stable disease; PD-I, program death-I; PR, partial response; LN, lymph node; PS, performance status; PD, progression of disease.

In addition, tumor volume was not associated with PFS (HR per $100 \mathrm{~cm}^{3}=1.1,95 \%$ CI $0.9,1.3, P=0.47$ ) (Table 3 ) or OS (HR per $100 \mathrm{~cm}^{3}=1.295 \%$ CI: $0.9,1.5, P=0.26$ ) (Table 4). Liver metastasis was associated with shorter survival ( $\mathrm{HR}=2.8,95 \% \mathrm{CI}: 1,7.9, P=0.05)$.

\section{Discussion}

Checkpoint inhibitors targeting the PD-1-PDL1 axis have substantially changed the landscape of the treatment of advanced metastatic stage NSCLC. Nivolumab, pembrolizumab, and atezolizumab have demonstrated superiority against docetaxel in the second-line setting for advanced metastatic NSCLC. ${ }^{8-10}$ A randomized Phase II study ${ }^{11}$ and subsequently the Phase III Keynote- 189 trial $^{12}$ showed the benefits of combining carboplatin/pemetrexed with pembrolizumab in the first-line setting and this combination has been approved for its use, regardless of PD-L1 expression. In addition, the Phase III KEYNOTE-407 trial showed 
Table 2 Associations of total volume with demographic and clinical characteristics

\begin{tabular}{|c|c|c|c|c|}
\hline & $\mathbf{N}$ & $\begin{array}{l}\text { Median } \\
\text { total vol }\end{array}$ & IQR & $P$-value \\
\hline Sex & & & & $0.21^{\mathrm{b}}$ \\
\hline Male & 67 & 66 & 14,116 & \\
\hline Female & 49 & 37 & 13,79 & \\
\hline Age & & & & $0.73^{c}$ \\
\hline$\leq 59$ yrs & 41 & 49 & 15,99 & \\
\hline $60-69$ yrs & 42 & 57 & II, III & \\
\hline$\geq 70$ yrs & 33 & 58 & 15,103 & \\
\hline Primary & & & & $0.56^{\mathrm{b}}$ \\
\hline Lung adeno & 77 & 53 & 13,105 & \\
\hline Lung squam & 33 & 63 & 28,111 & \\
\hline Lung poorly diff & 6 & 28 & 10,72 & \\
\hline Best response ${ }^{a}$ & & & & $0.61^{c}$ \\
\hline$P R$ & 26 & 43 & 13,88 & \\
\hline SD & 39 & 37 & 13,79 & \\
\hline PD & 34 & 60 & 18,84 & \\
\hline Mets category & & & & $0.07^{c}$ \\
\hline Mo/Mla & 45 & 35 & 13,72 & \\
\hline MIb & 12 & 59 & 22,116 & \\
\hline Mlc & 59 & 56 & 21,128 & \\
\hline Lines of previous $\mathrm{Tx}$ & & & & $0.70^{\mathrm{a}}$ \\
\hline 0 & 24 & 35 & 13,115 & \\
\hline 1 & 64 & 60 & 15,105 & \\
\hline 2 or more & 28 & 71 & 13,108 & \\
\hline Agent & & & & $0.29^{b}$ \\
\hline Pembro & 21 & 36 & 11,70 & \\
\hline Pembro + other & 30 & 43 & 14,132 & \\
\hline Nivo & 65 & 65 & 18,116 & \\
\hline On protocol & & & & $0.76^{\mathrm{b}}$ \\
\hline No & 71 & 51 & 13,101 & \\
\hline Yes & 45 & 63 & 15,123 & \\
\hline Hospitalizations w/i 6 wks $^{\mathrm{a}}$ & & & & $0.91^{\mathrm{b}}$ \\
\hline No & 78 & 47 & 13,88 & \\
\hline Yes & 25 & 55 & 15,80 & \\
\hline Reason discontinuation & & & & $0.14^{\mathrm{b}}$ \\
\hline PD, decline, PD-I AE & 96 & 56 & 15,113 & \\
\hline Completed therapy & 11 & 36 & 7,71 & \\
\hline Other & 7 & 193 & 2,462 & \\
\hline Unmeasurable lung & & & & $0.04^{b}$ \\
\hline No & 27 & 71 & 36,132 & \\
\hline Yes & 89 & 44 & 13,92 & \\
\hline Unmeasurable LN & & & & $0.33^{\mathrm{b}}$ \\
\hline No & 43 & 36 & 13,84 & \\
\hline Yes & 73 & 61 & 14,116 & \\
\hline
\end{tabular}

(Continued)
Table 2 (Continued).

\begin{tabular}{|l|l|l|l|l|}
\hline & N & $\begin{array}{l}\text { Median } \\
\text { total vol }\end{array}$ & IQR & P-value \\
\hline $\begin{array}{l}\text { Unmeasurable liver } \\
\text { No } \\
\text { Yes }\end{array}$ & 93 & 55 & 13,103 & $0.64^{\mathrm{b}}$ \\
\hline $\begin{array}{l}\text { Unmeasurable soft tissue } \\
\text { No } \\
\text { Yes }\end{array}$ & 23 & 37 & 18,138 & \\
\hline
\end{tabular}

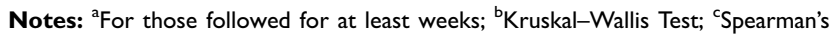
rank correlation.

Abbreviations: AE, adverse events; SD, stable disease; PD-I, program death-I; PR, partial response; LN, lymph node; PD, progression of disease.

improved PSF and OS when pembrolizumab was combined with carboplatin and paclitaxel/nabpaclitaxel, compared to chemotherapy alone in previously untreated metastatic squamous NSCLC patients. This was first-line chemotherapy irrespective of PD-L1 level. ${ }^{13}$ Single-agent pembrolizumab showed superiority compared to first-line chemotherapy in patients with tumors expressing PD-L1 $\geq 50 \%$. Pembrolizumab has gained FDA approval as a first-line single-agent therapy in this setting. ${ }^{14}$ Recently, single-agent Pembrolizumab was shown to improve OS even in patients with low PD-L1 expression (PD-L1 TPS level $\geq 1 \%$ ) compared to chemotherapy alone in untreated patients with locally advanced or metastatic NSCLC. This led to the FDA approval of pembrolizumab in this subset of patients as well. ${ }^{15}$

Although this new class of therapy offers hope for many advanced stage cancer patients, little is known on the characteristics of patients who are likely to respond.

PD-L1 expression has been one of the most extensively studied biomarkers in NSCLC. However, this marker is far from perfect, and is subject to several limitations Objective responses have been reported in both PD-L1 positive and negative NSCLCs. ${ }^{8,10-12,16,17}$ For example, the aforementioned Keynote-189 trial reported higher RRs with the pembrolizumab-chemotherapy combination group than in the placebo-chemotherapy combination group across all categories of PD-L1 tumor proportion score, although the greatest between-group difference in patients was seen in the PD-L1 high $\left(50 \%\right.$ or greater) group. ${ }^{12}$

The limitations of PD-L1 testing likely come from multiple variables. PD-L1 expression is thought to be regulated by various mechanisms, including the MAPK and PI3K pathways, multiple transcriptional factors such as HIF1 and 
Table 3 Tumor volume in association with PFS

\begin{tabular}{|c|c|c|}
\hline & HR (95\% Cl) & $P$-value \\
\hline Total volume (per $100 \mathrm{~cm}^{3}$ ) & I.I $(0.9,1.3)$ & 0.47 \\
\hline Sex & & 0.35 \\
\hline Male & 1.0 & \\
\hline Female & $1.2(0.8,1.9)$ & \\
\hline Age & & 0.59 \\
\hline$\leq 59 \mathrm{yrs}$ & 1.0 & \\
\hline $60-69$ yrs & I.2 $(0.7,1.9)$ & \\
\hline$\geq 70$ yrs & $0.9(0.5,1.5)$ & \\
\hline Primary & & 0.94 \\
\hline Lung adeno & 1.0 & \\
\hline Lung squam & $1.0(0.7,1.6)$ & \\
\hline Lung poorly diff & $0.9(0.2,2.4)$ & \\
\hline Best Response $^{a}$ & & $<0.001$ \\
\hline PR & 1.0 & \\
\hline SD & $4.6(2.3,9.4)$ & \\
\hline PD & $43.9(17.9,107.3)$ & \\
\hline Metastasizes & & 0.007 \\
\hline Mo/Mla & 1.0 & \\
\hline MIb & $1.0(0.5 .2 .3)$ & \\
\hline Mlc & $2.0(1.3,3.1)$ & \\
\hline Previous lines of $T x$ & & 0.005 \\
\hline 0 & 1.0 & \\
\hline 1 & $2.4(1.4,4.3)$ & \\
\hline 2 or more & $2.1(1.1,4.2)$ & \\
\hline Agent & & 0.006 \\
\hline Pembro & 1.0 & \\
\hline Pembro + other & $1.0(0.5,2.1)$ & \\
\hline Nivo & $2.0(1.1,3.8)$ & \\
\hline On protocol & & 0.006 \\
\hline No & 1.0 & \\
\hline Yes & $0.5(0.3,0.8)$ & \\
\hline Hospitalization $w / i ~ 6 w^{a}$ & & 0.001 \\
\hline No & 1.0 & \\
\hline Yes & $2.3(1.4,3.9)$ & \\
\hline Reason for discontinuation & & $<0.001$ \\
\hline PD, decline, PD-I AE & 1.0 & \\
\hline Completed Tx & $0.1((0.05,0.4)$ & \\
\hline Other & $0.4(0.1,1.2)$ & \\
\hline Unmeasurable lung & & 0.03 \\
\hline No & 1.0 & \\
\hline Yes & I.8 $(1.0,3.0)$ & \\
\hline Unmeasurable LN & & 0.55 \\
\hline No & 1.0 & \\
\hline Yes & $0.9(0.6,1.3)$ & \\
\hline
\end{tabular}

(Continued)
Table 3 (Continued).

\begin{tabular}{|l|l|l|}
\hline & HR (95\% Cl) & P-value \\
\hline $\begin{array}{l}\text { Unmeasurable Liver } \\
\text { No } \\
\text { Yes }\end{array}$ & 1.0 & 0.06 \\
\hline Unmeasurable soft tissue & $1.7(1.0,2.8)$ & \\
No & & 0.41 \\
Yes & 1.0 & \\
\hline $\begin{array}{l}\left.\text { Lung (per } 100 \mathrm{~cm}^{3}\right)>2 \mathrm{~cm} \\
\left.\text { LN (per } 100 \mathrm{~cm}^{3}\right)>1.5 \mathrm{~cm}\end{array}$ & $1.2(0.8,1.9)$ & \\
Liver (per $\left.100 \mathrm{~cm}^{3}\right)>2 \mathrm{~cm}$ & $0.8(0.4,1.7)$ & 0.59 \\
Soft tissue $\left(\right.$ per $\left.100 \mathrm{~cm}^{3}\right)>2 \mathrm{~cm}$ & $1.8(1.1,2.9)$ & 0.11 \\
\hline
\end{tabular}

Notes: a For those followed for at least weeks.

Abbreviations: $A E$, adverse events; SD, stable disease; PD-I, program death-I; PR, partial response; PFS, progression free survival; LN, lymph node; PD, progression of disease.

STAT3 as well as epigenetic factors. ${ }^{18}$ In addition, PD-L1 expression can be transient. Intra-patient, as well as intratumor heterogeneity in PD-L1 expression is possible. ${ }^{19}$

Another challenge is the poor uniformity, and PD-L1 positivity thresholds of the various immunohistochemistry testing methods. ${ }^{20}$ Furthermore, PD-L1 expression alone does not take into account other factors that could influence anti-tumor response such as immune-cell engagement in the tumor micro-environment and the presence of other concurrent suppressive pathways. ${ }^{21}$ Despite these limitations, PD-L1 expression is one of the few widely available biomarkers that has been most extensively studied for NSCLC at this time. Testing for PD-L1 is considered to be standard of care for patients with newly diagnosed advanced metastatic NSCLC. ${ }^{22}$

Since mutations are considered to produce neoantigens that could elicit an immune response, somatic mutational burden is another predictive biomarker that is being explored in this setting. Tumors with high rates of somatic mutations such as melanoma, NSCLC, and microsatellite-unstable colorectal cancer have been found to have a higher probability of benefiting from immune checkpoint blockade than those with lower rates of somatic mutations. ${ }^{23,24}$ In the CheckMate 227 study, Hellmann et al showed that among patients with NSCLC and a high tumor mutational burden ( $\geq 10$ mutations per megabase determined by the FoundationOne CDx assay), the PFS was significantly longer with first-line nivolumab plus ipilimumab than with chemotherapy, irrespective of their PD-L1 expression level. ${ }^{17}$

Tumor-infiltrating lymphocytes may also serve as a prognostic biomarker. In a melanoma study assessing 40 
Table 4 Tumor volume in association with OS

\begin{tabular}{|c|c|c|}
\hline & HR (95\% CI) & $P$-value \\
\hline Total volume (per $100 \mathrm{~cm}^{3}$ ) & $1.2(0.9,1.5)$ & 0.26 \\
\hline $\begin{array}{l}\text { Sex } \\
\qquad \text { Male } \\
\text { Female }\end{array}$ & $\begin{array}{l}1.0 \\
1.4(0.8,2.3)\end{array}$ & 0.24 \\
\hline 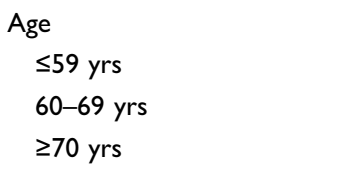 & $\begin{array}{l}1.0 \\
1.2(0.6,2.2) \\
0.9(0.4,1.7)\end{array}$ & 0.65 \\
\hline $\begin{array}{l}\text { Primary } \\
\text { Lung adeno } \\
\text { Lung squam } \\
\text { Lung poorly diff }\end{array}$ & $\begin{array}{l}1.0 \\
0.8(0.4,1.5) \\
1.2(0.4,4.0)\end{array}$ & 0.72 \\
\hline $\begin{array}{l}\text { Best response }{ }^{\mathrm{a}} \\
\text { PR } \\
\text { SD } \\
\text { PD }\end{array}$ & $\begin{array}{l}1.0 \\
5.6(1.6,19.1) \\
17.4(5.1,59.3)\end{array}$ & $<0.001$ \\
\hline $\begin{array}{l}\text { Metastasizes } \\
\text { MO/Mla } \\
\text { MIb } \\
\text { Mlc }\end{array}$ & $\begin{array}{l}1.0 \\
1.0(0.3,3.1) \\
2.2(1.3,4.4)\end{array}$ & 0.008 \\
\hline $\begin{array}{l}\text { Previous lines of } T x \\
0 \\
1 \\
2 \text { or more }\end{array}$ & $\begin{array}{l}1.0 \\
2.3(1.0,5.3) \\
4.4(1.9,10.6)\end{array}$ & 0.001 \\
\hline $\begin{array}{l}\text { Agent } \\
\text { Pembro } \\
\text { Pembro + other } \\
\text { Nivo }\end{array}$ & $\begin{array}{l}1.0 \\
0.9(0.4,2.3) \\
1.6(0.7,3.5)\end{array}$ & 0.19 \\
\hline $\begin{array}{l}\text { On protocol } \\
\text { No } \\
\text { Yes }\end{array}$ & $\begin{array}{l}1.0 \\
0.6(0.4, \mathrm{I} . \mathrm{I})\end{array}$ & 0.10 \\
\hline $\begin{array}{l}\text { Hospitalization } w / i 6 w^{a} \\
\text { No } \\
\text { Yes }\end{array}$ & $\begin{array}{l}1.0 \\
6.0(3.2,11.0)\end{array}$ & $<0.001$ \\
\hline $\begin{array}{l}\text { Reason for discontinuation } \\
\text { PD, decline, PD-I AE } \\
\text { Completed Tx } \\
\text { Other }\end{array}$ & $\begin{array}{l}1.0 \\
- \\
-\end{array}$ & - \\
\hline $\begin{array}{l}\text { Unmeasurable lung } \\
\text { No } \\
\text { Yes }\end{array}$ & $\begin{array}{l}1.0 \\
2.2(1.0,4.7)\end{array}$ & 0.02 \\
\hline $\begin{array}{l}\text { Unmeasurable LN } \\
\text { No } \\
\text { Yes }\end{array}$ & $\begin{array}{l}1.0 \\
0.9(0.5,1.6)\end{array}$ & 0.74 \\
\hline
\end{tabular}

(Continued)
Table 4 (Continued).

\begin{tabular}{|l|l|l|}
\hline & HR (95\% Cl) & P-value \\
\hline $\begin{array}{l}\text { Unmeasurable liver } \\
\text { No }\end{array}$ & 1.0 & 0.09 \\
Yes & $1.7(0.9,3.3)$ & \\
\hline Unmeasurable soft tissue & & 0.46 \\
No & 1.0 & \\
Yes & $1.3(0.7,2.3)$ & \\
\hline Lung (per $\left.100 \mathrm{~cm}^{3}\right) 2 \mathrm{~cm}$ & $1.1(0.8,1.4)$ & 0.54 \\
LN (per $\left.100 \mathrm{~cm}^{3}\right) 1.5 \mathrm{~cm}$ & $1.1(0.5,2.6)$ & 0.77 \\
Liver (per $\left.100 \mathrm{~cm}^{3}\right) 2 \mathrm{~cm}$ & $2.8(1.0,7.9)$ & 0.05 \\
Soft tissue $\left(\right.$ per $\left.100 \mathrm{~cm}^{3}\right) 2 \mathrm{~cm}$ & $1.3(0.5,3.3)$ & 0.66 \\
\hline
\end{tabular}

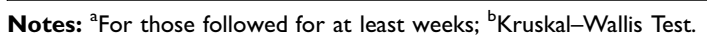
Abbreviations: $A E$, adverse events; $S D$, stable disease; PD-I, program death-I; PR, partial response; OS, overall survival; LN, lymph node; PD, progression of disease.

patients, a RR of $79 \%$ was demonstrated when pre-treatment tumor biopsies had $>20 \%$ of tumor-infiltrating PD-1 high and CTLA-4 high CD8 T cells, whereas there were no responders in patients with fewer than $20 \%$ infiltrating PD1 high and CTLA-4 high CD8 T cells. ${ }^{25}$ However, one must be cautious about the use of tumor-infiltrating lymphocytes in clinical practice, because lymphocyte infiltration is also known to appear upon disease progression. Detection techniques and cut-off values have not been standardized.

Furthermore, Tumeh et al investigated whether the narrow repertoire of $\mathrm{T}$ cell receptors correlated with response to pembrolizumab in patients with melanoma. Their observations showed that T-cell receptor beta chain usage was more restricted in responders versus those who were showing signs of progression; suggesting that those whose tumor has a low tumor-infiltrating lymphocyte density may still benefit from anti-PD-1 therapy if the tumorinfiltrating lymphocyte population has restricted T-cell receptor clonality specific to the tumor antigen. ${ }^{26}$

Many studies have evaluated the association between tumor burden and response to therapy. The classic example is metastatic renal cell carcinoma, where prior cytoreductive nephrectomy has been associated with a survival advantage and improved response to systemic therapy, including antiVEGF treatment and immunotherapy like INF- $\alpha .^{3-6}$ In a trial by Flanigan et al, nephrectomy prior to INF- $\alpha-2 b$ treatment was associated with significantly improved median OS (8.1 vs 11.1 months). ${ }^{3}$ Similarly, a trial by Mickisch et al, showed improved survival and increased time to progression in patients who underwent nephrectomy prior to INF- $\alpha$ treatment compared to INF- $\alpha$ alone. ${ }^{4}$ In addition, there have been reports 
for improved survival in the combination of nephrectomy and IL-2 therapy. ${ }^{27,28}$

In melanoma studies, patients with high $\mathrm{LDH}$ levels had lower RRs to immunotherapy when compared to those without high LDH levels. ${ }^{29,30}$ While non-specific, as LDH is easily detected in serum during tissue turnover and damage, this has been a classic marker for tumor burden.

Tumor volumes, oftentimes derived through calculations of target volumes, have been previously studied in the field of radiation oncology. Techniques to overcome respiratory motion have been an area of focus especially in the treatment planning of lung cancer. ${ }^{31,32}$ The prognostic value of PTV has also been studied in stage III NSCLC patients undergoing definitive chemoradiotherapy. In this single institutional study of 52 patients, tumor volumes were measured four times during the course of their treatment and found that greater relative tumor volume reduction during treatment correlates with improved disease control and OS. ${ }^{33}$ Through their analysis of 88 patients, Kuo et al calculated the decrease of tumor volume post-chemotherapy in advanced NSCLC. The authors reported the efficacy of their proposed survival prediction index through tumor volume measurements, but these findings are yet to be validated. ${ }^{34}$

To our knowledge, our study is the first to estimate an association between PTV and best response in NSCLC patients treated with immunotherapy. The association between PTV and best response, considered as an ordered 4-category variable was not strong. Neither were PTV, age, sex, PD-1 agent, protocol status associated with OS (Table 2). Best response, metastasis category, previous lines of therapy, hospitalization within 6 weeks and having liver metastasis $>2 \mathrm{~cm}$ in size were associated with shorter survival. Contrary to our hypothesis, PTV in NSCLC did not prove to be a strong predictor of response. As demonstrated in Figure 2 although some patients with PR had low PTV, some of those with high PTV did have a response, thereby suggesting the presence of other factors contributing to response. As shown in Figure 3, there were no associations of PTV based on the lung tumor histology.

Interestingly, Huang et al recently reported that the magnitude of reinvigoration of circulating exhausted-phenotype CD8 T cells calibrated to pretreatment tumor burden was associated with clinical response in advanced melanoma patients. ${ }^{7}$ In this study, tumor burden was defined as the sum of the long axis of all measurable lesions reported on the pretreatment imaging reports. The authors did comment that the tumor burden alone was not a perfect predictor of response to anti-PD-1 therapy and that there were likely other parameters, such as anatomical location of metastases, PD-L1 expression and mutational phenotype, which may add further to resolve the relationship between T-cell reinvigoration and tumor burden.

In our study, liver metastasis prior to treatment was associated with significantly shorter survival. This result is consistent with reports from previous studies with Riihimäki et al showing that mortality was 1.53 fold higher for patients with liver metastasis than for those with brain metastasis $(P<0.05) .{ }^{35}$ Similarly, Tamura et al demonstrated that the mortality was 1.55 fold higher for patients with liver metastasis

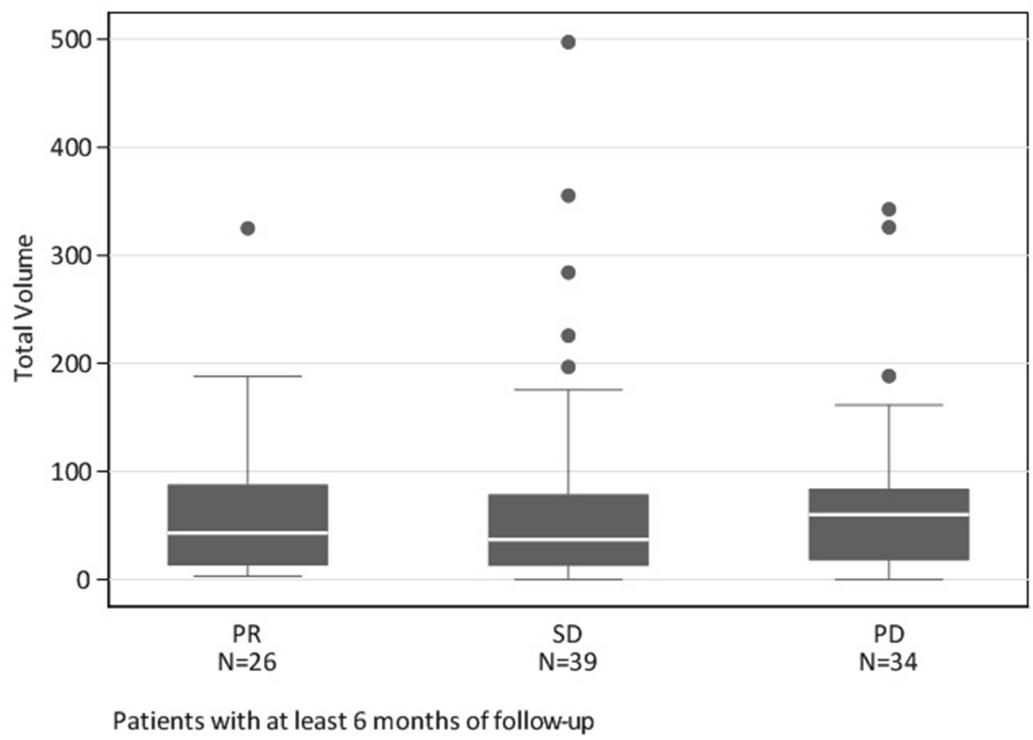

Figure 2 Box plots illustrating the distribution of pretreatment tumor volume according to best response. 


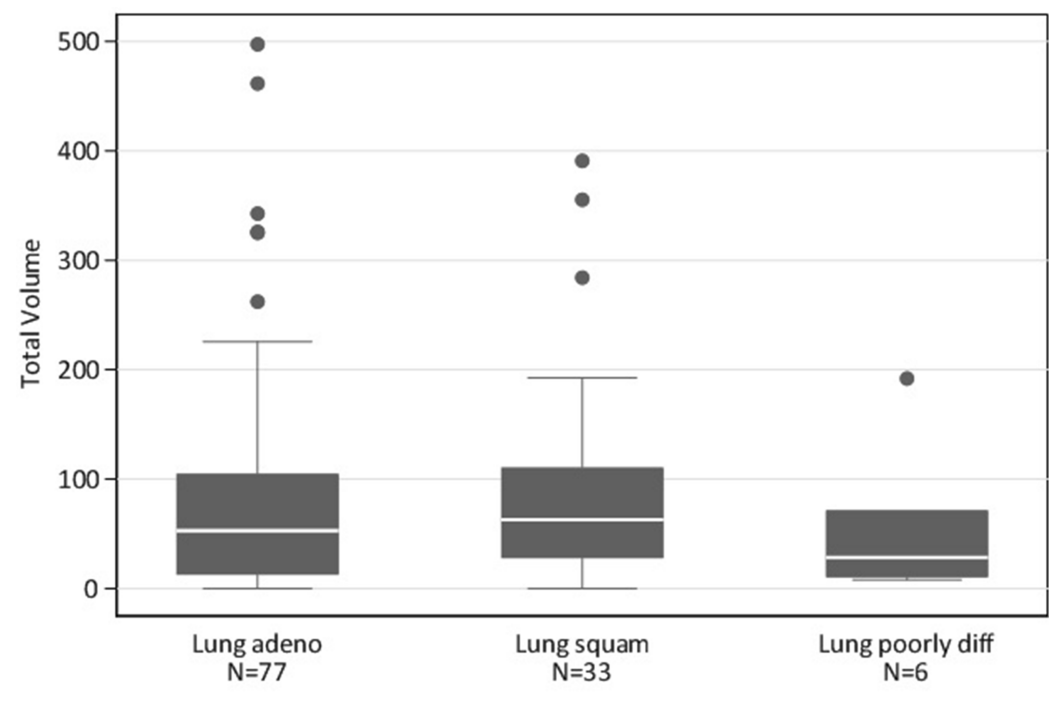

All patients

Figure 3 Boxplots illustrating the distribution of pretreatment tumor volume according to lung tumor histology.

than for those with other distant metastasis $(P<0.001) .{ }^{36}$ As demonstrated, liver metastases in NSCLC are likely a negative prognostic factor regardless of the use of immunotherapy.

\section{Conclusion}

Contrary to our hypothesis, PTV in NSCLC did not prove to be a predictor of response to PD-1 inhibitors but having liver metastasis prior to treatment was associated with significantly shorter survival.

\section{Ethics approval/copyright}

This study was reviewed and approved by the Wayne State University's Institutional Review Board (approval \# 062616M1E). The database held only de-identified patient data.

\section{Abbreviations}

INF, interferon- $\alpha$; NSCLC, non-small cell lung cancer; OS, overall survival; PR, partial response; PD-1, program death-1; PFS, progression-free survival, PTV, pretreatment tumor volume; RR, response rate; $\mathrm{SD}$, stable disease.

\section{Acknowledgments}

The authors wish to thank the patients and the families who were treated at our site. The preliminary results of this manuscript were presented as a poster on 10/17/2017 at IASLC 18th World Lung Cancer Conference at Yokohama, Japan. This study did not receive any funding.

\section{Author contributions}

The first and last authors contributed to the conception, data acquisition and prepared the first draft. All authors contributed to data analysis, drafting or revising the article, gave final approval of the version to be published, and agree to be accountable for all aspects of the work.

\section{Disclosure}

Dr Antoinette Wozniak reports grants, personal fees from Boehringer Ingelheim, personal fees from Astra Zeneca, DSMB from BeyondSpring, DSMB from HUYA Bioscience, personal fees from Takeda, personal fees from Karyopharm Therapeutics, personal fees from Premier Inc, during the conduct of the study. Dr Shirish Gadgeel reports personal fees from Boehringer-Ingelheim, non-financial support from Astra-Zeneca, non-financial support from Novocure, non-financial support from Takeda, non-financial support from Genentech/Roche, non-financial support from Bristol Myers-Squibb, nonfinancial support from Xcovery, non-financial support from Abbvie, outside the submitted work. The authors report no other conflicts of interest in this work.

\section{References}

1. Bazan JG, Duan F, Snyder BS, et al. Metabolic tumor volume predicts overall survival in patients with stage III non-small cell lung cancer treated on ACRIN 6668/RTOG 0235: locally advanced non-small cell lung cancer. Int J Radiat Oncol Biol Phys. 2014;90(5):S3-S4. doi:10.1016/j.ijrobp.2014.08.027 
2. Lee P, Bazan JG, Lavori PW, et al. Metabolic tumor volume is an independent prognostic factor in patients treated definitively for nonsmall-cell lung cancer. Clin Lung Cancer. 2012;13(1):52-58. doi:10.1016/j.cllc.2011.05.001

3. Flanigan RC, Salmon SE, Blumenstein BA, et al. Nephrectomy followed by interferon alfa- $2 b$ compared with interferon alfa- $2 b$ alone for metastatic renal-cell cancer. $N$ Engl J Med. 2001;345 (23):1655-1659. doi:10.1056/NEJMoa003013

4. Mickisch GH, Garin A, van Poppel H, de Prijck L, Sylvester R. Radical nephrectomy plus interferon-alfa-based immunotherapy compared with interferon alfa alone in metastatic renal-cell carcinoma: a randomised trial. Lancet. 2001;358(9286):966-970. doi:10.1016/ s0140-6736(01)06103-7

5. Choueiri TK, Xie W, Kollmannsberger C, et al. The impact of cytoreductive nephrectomy on survival of patients with metastatic renal cell carcinoma receiving vascular endothelial growth factor targeted therapy. J Urol. 2011;185(1):60-66. doi:10.1016/j.juro.2010. 09.012

6. Hanna N, Sun M, Meyer CP, et al. Survival analyses of patients with metastatic renal cancer treated with targeted therapy with or without cytoreductive nephrectomy: a national cancer data base study. J Clin Oncol. 2016;34(27):3267-3275. doi:10.1200/JCO.2016.66.7931

7. Huang AC, Postow MA, Orlowski RJ, et al. T-cell invigoration to tumour burden ration associated with anti-PD-1 response. Nature. 2017;545(7652):60-65. doi:10.1038/nature22079

8. Borghaei H, Paz-Ares L, Horn L, et al. Nivolumab versus docetaxel in advanced nonsquamous non-small-cell lung cancer. $N$ Engl J Med. 2015;373(17):1627-1639. doi:10.1056/NEJMoa1507643

9. Herbst RS, Baas P, Kim DW, et al. Pembrolizumab versus docetaxel for previously treated, PD-L1-positive, advanced non-small-cell lung cancer (KEYNOTE-010): a randomised controlled trial. Lancet. 2016;387(10027):1540-1550. doi:10.1016/S0140-6736(15)01281-7

10. Brahmer J, Reckamp KL, Baas P, et al. Nivolumab versus docetaxel in advanced squamous-cell non-small-cell lung cancer. $N$ Engl J Med. 2015;373(2):123-135. doi:10.1056/NEJMoa1504627

11. Langer CJ, Gadgeel SM, Borghaei H, et al. Carboplatin and pemetrexed with or without pembrolizumab for advanced, non-squamous non-small-cell lung cancer: a randomised, phase 2 cohort of the openlabel KEYNOTE-021 study. Lancet Oncol. 2016;17(11):1497-1508. doi:10.1016/S1470-2045(16)30498-3

12. Gandhi L, Rodriguez-Abreu D, Gadgeel S, et al. Pembrolizumab plus chemotherapy in metastatic non-small-cell lung cancer. $N$ Engl J Med. 2018;378(22):2078-2092. doi:10.1056/NEJMoa1801005

13. Paz-Ares L, Luft A, Vicente D, et al. Pembrolizumab plus chemotherapy for squamous non-small-cell lung cancer. $N \mathrm{Engl} \mathrm{J} \mathrm{Med.}$ 2018;379(21):2040-2051. doi:10.1056/NEJMoa1810865

14. Reck M, Rodriguez-Abreu D, Robinson AG, et al. Pembrolizumab versus chemotherapy for PD-L1-positive non-small-cell lung cancer. $N$ Engl J Med. 2016;375(19):1823-1833. doi:10.1056/NEJMoa160 6774

15. Mok TSK, Wu YL, Kudaba I, et al. Pembrolizumab versus chemotherapy for previously untreated, PD-L1-expressing, locally advanced or metastatic non-small-cell lung cancer (KEYNOTE042): a randomised, open-label, controlled, phase 3 trial. Lancet. 2019;393(10183):1819-1830. doi:10.1016/S0140-6736(18)32409-7

16. Rizvi NA, Mazieres J, Planchard D, et al. Activity and safety of nivolumab, an anti-PD-1 immune checkpoint inhibitor, for patients with advanced, refractory squamous non-small-cell lung cancer (CheckMate 063): a phase 2, single-arm trial. Lancet Oncol. 2015;16(3):257-265. doi:10.1016/S1470-2045(15)70054-9

17. Hellmann MD, Ciuleanu TE, Pluzanski A, et al. Nivolumab plus Ipilimumab in lung cancer with a high tumor mutational burden. $N$ Engl J Med. 2018;378(22):2093-2104. doi:10.1056/NEJMoa1801946

18. Chen J, Jiang CC, Jin L, Zhang XD. Regulation of PD-L1: a novel role of pro-survival signalling in cancer. Ann Oncol. 2016;27(3):409416. doi:10.1093/annonc/mdv615
19. Mansfield AS, Murphy SJ, Peikert T, et al. Heterogeneity of programmed cell death ligand 1 expression in multifocal lung cancer. Clin Cancer Res. 2016;22(9):2177-2182. doi:10.1158/1078-0432. CCR-15-2246

20. Tsao MS, Kerr KM, Kockx M, et al. PD-L1 immunohistochemistry comparability study in real-life clinical samples: results of blueprint Phase 2 project. $J$ Thorac Oncol. 2018;13(9):1302-1311. doi:10.1016/j.jtho.2018.05.013

21. Gibney GT, Weiner LM, Atkins MB. Predictive biomarkers for checkpoint inhibitor-based immunotherapy. Lancet Oncol. 2016;17 (12):e542-e551. doi:10.1016/S1470-2045(16)30406-5

22. NCCN Clinical Practice Guidelines in Oncology-Non-Small Cell Lung Cancer. Version 7. 2019. Available from: https://www.ncen. org/professionals/physician_gls/pdf/nscl.pdf. Accessed Spetember $02,2019$.

23. Rizvi NA, Hellmann MD, Snyder A, et al. Cancer immunology. Mutational landscape determines sensitivity to PD-1 blockade in non-small cell lung cancer. Science. 2015;348(6230):124-128. doi:10.1126/science.aaa1348

24. Le DT, Durham JN, Smith KN, et al. Mismatch repair deficiency predicts response of solid tumors to PD-1 blockade. Science. 2017;357(6349):409-413. doi:10.1126/science.aan6733

25. Daud AI, Loo K, Pauli ML, et al. Tumor immune profiling predicts response to anti-PD-1 therapy in human melanoma. J Clin Invest. 2016;126(9):3447-3452. doi:10.1172/JCI87324

26. Tumeh PC, Harview CL, Yearley JH, et al. PD-1 blockade induces responses by inhibiting adaptive immune resistance. Nature. 2014;515(7528):568-571. doi:10.1038/nature13954

27. Franklin JR, Figlin R, Rauch J, et al. Cytoreductive surgery in the management of metastatic renal cell carcinoma: the UCLA experience. Semin Urol Oncol. 1996;14(4):230-236.

28. Mani S, Todd MB, Katz K, Poo WJ. Prognostic factors for survival in patients with metastatic renal cancer treated with biological response modifiers. J Urol. 1995;154(1):35-40.

29. Ribas A, Hamid O, Daud A, et al. Association of pembrolizumab with tumor response and survival among patients with advanced melanoma. JAMA. 2016;315(15):1600-1609. doi:10.1001/jama.2016.4059

30. Long GV, Blank C, Ribas A, et al. Impact of baseline serum lactate dehydrogenase concentration on the efficacy of pembrolizumab and ipilimumab in patients with advanced melanoma: data from KEYNOTE-006. Eur J Cancer. 2017;72:S122-S123. doi:10.1016/ $\mathrm{S} 0959-8049(17) 30482-3$

31. Nishibuchi I, Kimura T, Nakashima T, et al. Time-adjusted internal target volume: a novel approach focusing on heterogeneity of tumor motion based on 4-dimensional computed tomography imaging for radiation therapy planning of lung cancer. Int J Radiat Oncol Biol Phys. 2014;89(5):1129-1137. doi:10.1016/j.ijrobp.2014.04.050

32. Sun Y, Ge H, Cheng S, et al. Evaluation of interfractional variation of the centroid position and volume of internal target volume during stereotactic body radiotherapy of lung cancer using cone-beam computed tomography. J Appl Clin Med Phys. 2016;17(2):461-472. doi:10.1120/jacmp.v17i2.5835

33. Wald P, Mo X, Barney C, et al. Prognostic value of primary tumor volume changes on $\mathrm{kV}$-CBCT during definitive chemoradiotherapy for stage III non-small cell lung cancer. J Thorac Oncol. 2017;12 (12):1779-1787. doi:10.1016/j.jtho.2017.08.010

34. Kuo CJ, Ke BH, Wu NY, et al. Prognostic value of tumor volume for patients with advanced lung cancer treated with chemotherapy. Comput Methods Programs Biomed. 2017;144:165-177. doi:10.1016/j.cmpb.2017.03.021

35. Riihimaki M, Hemminki A, Fallah M, et al. Metastatic sites and survival in lung cancer. Lung Cancer. 2014;86(1):78-84. doi:10.1016/j.lungcan.2014.07.020

36. Tamura T, Kurishima K, Nakazawa K, et al. Specific organ metastases and survival in metastatic non-small-cell lung cancer. Mol Clin Oncol. 2015;3(1):217-221. doi:10.3892/mco.2014.410 


\section{Publish your work in this journal}

Lung Cancer: Targets and Therapy is an international, peerreviewed, open access journal focusing on lung cancer research, identification of therapeutic targets and the optimal use of preventative and integrated treatment interventions to achieve improved outcomes, enhanced survival and quality of life for the cancer patient. Specific topics covered in the journal include: Epidemiology, detection and screening; Cellular research and biomarkers; Identification of biotargets and agents with novel mechanisms of action; Optimal clinical use of existing anticancer agents, including combination therapies; Radiation and surgery; Palliative care; Patient adherence, quality of life, satisfaction; Health economic evaluations. 